\title{
2D Shallow Water Model for Dam Break and Column Interactions
}

\author{
Putu Indah Dianti Putri ${ }^{1 *}$, Rifqi Fauzan Iskandar', Mohammad Bagus Adityawan², \\ Hadi Kardhana ${ }^{2}$, Dian Indrawati ${ }^{3}$ \\ ${ }^{1}$ Graduate School of Civil Engineering, Bandung Institute of Technology, Bandung INDONESIA \\ Jalan Ganesha 10, Bandung 40132 \\ ${ }^{2}$ Water Resources Engineering Research Group, Bandung Institute of Technology, Bandung, INDONESIA \\ Jalan Ganesha 10, Bandung 40132 \\ ${ }^{3}$ Departement of Civil Engineering, Universitas Jenderal Achmad Yani, Cimahi \\ Jalan Terusan Jend. Sudirman, Cimahi 40533 \\ *Corresponding authors: indahdput@gmail.com
}

SUBMITTED 18 February 2020 REVISED 6 April 2020 ACCEPTED 5 May 2020

\begin{abstract}
Dam break causes disastrous effects on the surrounding area, especially at the downstream, therefore, there is a need for accurate and timely predictions of dam break propagation to prevent both property damage and loss of life. This study aimed to determine the movement of dam-break flow in the downstream area by solving the Shallow Water Equations (SWE) or Saint Venant Equations which are based on the conservation of mass and momentum derived from Navier Stokes equation. The model was generated using a finite difference scheme which is the most common and simplest method for dam-break modeling while Forward Time Central Space (FTCS) numerical scheme was applied to simulate two-dimensional SWE. Moreover, the accuracy of the numerical model was checked by comparing its results with the analytic results of one-dimensional cases and a relatively small value of error was found in comparison to the analytic models as indicated with the RMSE values close to 0 . The numerical to the two-dimensional models were also compared to a simple dam break in a flume and dam break with column interactions and the wave propagation in both cases was observed to become very close at a certain time. The model, however, used numerical filter (Hansen) to reduce the oscillations or numerical instability. The simulation and analysis, therefore, showed the ability of the numerical scheme of FTCS to resolve both cases of the simple dam break and dam break with column interactions in the Two-dimensional Shallow Water.
\end{abstract}

KEYWORDS Dam Break, Two-dimensional, Shallow Water Equations, FTCS, Numerical Instability

(c) The Author(s) 2020. This article is distributed under a Creative Commons Attribution-ShareAlike 4.0 International license.

\section{INTRODUCTION}

Hydraulic dam plays an important role in flood control and power generation, thereby, providing great benefits to both national and domestic economy. The collapse of a dam, however, has the ability to cause catastrophic effects on its surrounding and downstream areas. This means an accurate and timely prediction of dam-break flow propagation has both theoretical and engineering importance in preventing property damage and loss of life (Chen, et al., 2005). Dam failure is normally caused by several factors including geotechnical failure, the strength of construction, excess pore water pressure, quality of material used for construction, error in construction planning, natural disasters, and others (Harlan, et al., 2019).

The modeling of dam-break flow in downstream areas is usually investigated by solving the shallow water equations (SWE) or Saint-Venant Equations which are based on the conservation of mass and momentum and derived from sectionaveraging of the depth-averaged threedimensional Navier Stokes equation (Sinha, et al., 2013). It is possible to solve this equation numerically using finite difference, finite volume, 
or finite element methods (Harlan, et al., 2019). The finite difference is one of the most common and simplest methods for dam-break modeling and has been used in the numerical study of onedimensional and two-dimensional dam-break by Farid, et al. (2016) and Kusuma, et al. (2008). The results showed the shock wave caused numerical oscillations, especially for lower-order schemes, and this led to the need for a numerical filter.

This study was conducted by investigating the FTCS (Forward Time Central Space) numerical scheme to determine the movement of water flow and its effect on the downstream area causing dam break. Moreover, Hansen Filter was used to reduce the numerical instability or oscillation in the model as observed in Adityawan and Tanaka (2012) and Zendrato, et al. (2019). The study aimed to determine the application of the FTCS numerical scheme to the problem of a simple dam break and a dam break coupled with column interaction. The difference between these two cases tested is the obstacle, in the form of a column, which was placed at the downstream of the dam in Case 2.

\section{GOVERNING EQUATIONS}

The two-dimensional Saint Venant Equations for the dam break case consists of mass conservation or continuity and momentum conservation equations ( $x$ and $y$ direction) as shown in Equation (1) to (3).

Continuity:

$\frac{\partial h}{\partial t}+\frac{\partial(h u)}{\partial x}+\frac{\partial(h v)}{\partial y}=0$

Momentum $x$-direction:

$\frac{\partial u}{\partial t}+u \frac{\partial u}{\partial x}+v \frac{\partial u}{\partial y}+g \frac{\partial h}{\partial x}-g\left(S o_{x}-S f_{x}\right)=0$

Momentum y-direction:

$\frac{\partial v}{\partial t}+v \frac{\partial v}{\partial y}+u \frac{\partial v}{\partial x}+g \frac{\partial h}{\partial y}-g\left(S o_{y}-S f_{y}\right)=0$
Where, $h$ is water depth, $u$ and $v$ are the velocity of $x$-direction and $y$-direction respectively, $g$ is the gravitational acceleration, $S o_{x}$ and $S o_{y}$ are depth gradient for $x$-direction and $y$-direction, $S f_{x}$ and $S f_{y}$ are energy grade lines for $x$-direction and $\mathrm{y}$-direction. The depth gradient is defined in Equation (4) and (5).

$S o_{x}=-\frac{\partial h_{0}}{\partial x}$

$S o_{y}=-\frac{\partial h_{0}}{\partial y}$

where $h 0$ is the bed height.

The energy grade line was calculated using Equation (6) and (7).

$S f_{x}=\frac{n^{2} u \sqrt{u^{2}+v^{2}}}{h^{4 / 3}}$

$S f_{y}=\frac{n^{2} v \sqrt{u^{2}+v^{2}}}{h^{4 / 3}}$

where $n$ is the manning's roughness coefficient.

In the FTCS scheme, the time derivative was approached using the first order forward difference while the space derivative used a central difference. The Saint Venant Equations discretization with FTCS is provided in Equation (8) to (10).

Continuity:

$h_{i, j}^{t+1}=h_{i, j}^{t}-\frac{\Delta t}{2 \Delta x}\left(U_{i+1, j}^{t} \cdot h_{i+1, j}^{t}-U_{i-1, j}^{t} \cdot h_{i-1, j}^{t}\right)-\frac{\Delta t}{2 \Delta y}\left(V_{i, j+1}^{t} \cdot h_{i, j+1}^{t}-\right.$ $\left.V_{i, j-1}^{t} \cdot h_{i, j-1}^{t}\right)$

Momentum $x$-direction:

$U_{i, j}^{t+1}=U_{i, j}^{t}-\frac{\Delta t}{2 \Delta x} U_{i, j}^{t}\left(U_{i+1, j}^{t}-U_{i-1, j}^{t}\right)-\frac{\Delta t}{2 \Delta y} V_{i, j}^{t}\left(U_{i, j+1}^{t}-U_{i, j-1}^{t}\right)-$

$\frac{g \Delta t}{2 \Delta x}\left(h_{i+1, j}^{t}-h_{i+1, j}^{t}\right)+g\left(S o_{x}-S f_{x}\right)$

Momentum y-direction:

$V_{i, j}^{t+1}=V_{i, j}^{t}-\frac{\Delta t}{2 \Delta y} V_{i, j}^{t}\left(V_{i, j+1}^{t}-V_{i, j-1}^{t}\right)-\frac{\Delta t}{2 \Delta x} U_{i, j}^{t}\left(V_{i+1, j}^{t}-V_{i-1, j}^{t}\right)-$

$\frac{g \Delta t}{2 \Delta y}\left(h_{i, j+1}^{t}-h_{i, j-1}^{t}\right)+g\left(S o_{y}-S f_{y}\right)$ 
A numerical Hansen Filter (1962) was also adopted in the dam-break modeling of this study (Adityawan and Tanaka, 2012; Zendrato, et al., 2019; Maitsa, et al., 2019) to reduce the numerical instability or oscillation caused by the shock wave in the downstream of the dam in the calculation. The filter acted as an artificial dissipation and applied at each time step of each node. Moreover, the water velocity ( $x$ and $y$ directions) and water depth were the two filtered parameters that used Equation (11) with $C$ value set to 0.99 and $F$ corresponded to the filtered parameters.

$F_{i, j}=C F_{i, j}+(1-C) \frac{\left(F_{i-1, j}+F_{i+1, j}+F_{i, j-1}+F_{i, j+1}\right)}{4}$

\section{PROBLEM SET-UP AND BOUNDARY CONDITION}

The case simulated was a two-dimensional test on the interaction of the dam failure with the column. The simulation for both cases 1 and 2 was conducted to continue a previous study by Sinha, et al. (2013) which used a model based on SPH (Smooth Particle Hydrodynamics).

\subsection{Test Case: A Theoretical Case of a Dam Break in a Flume or Simple Dam Break}

This test case consisted of a dam break problem over a wet bed with the computational domain designed to be $2 \mathrm{~m}$ long as shown in Figure 1. The water depth for the first $0.4 \mathrm{~m}$ was $0.15 \mathrm{~m}$ followed by $0.015 \mathrm{~m}$ to provide a ratio of 10 between the head and tailwater. Moreover, the dam break phenomenon was simulated by letting the water at the upstream end collapse at $t=0.0$ second.
The numerical flume was set using length $x$-direction $(L x)=2.00 \mathrm{~cm}$, length $y$-direction $(L y)=0.16 \mathrm{~cm}$, time interval $(\Delta t)=0.00001 \mathrm{~s}$, grid spacing $x$-direction $(\Delta x)=0.005 \mathrm{~cm}$ and $y$-direction $(\Delta y)=0.005 \mathrm{~cm}$. There was no bed friction, therefore, the manning coefficient $(n)=0$.

The boundary condition for all sides was defined as wall boundaries with the water level on the wall considered to have the same height as the previous grid. Moreover, the velocities of water in the corner of the wall in $x$ and $y$ directions were equal to 0 .

\subsection{Test Case: Dam Break Flow on a Structure}

The domain set up for this simulation consisted of $1.6 \mathrm{~m}$ long channel with the initial $0.4 \mathrm{~m}$ having a water depth of $0.3825 \mathrm{~m}$ while the rest had $0.0225 \mathrm{~m}$. A prismatic column with equal length and width of $0.12 \mathrm{~m}$ was located at $0.9 \mathrm{~m}$ from the upstream end of the channel. The computational set-up is appropriately shown in Figure 2 and the water column located at the upstream end is allowed to collapse at $t=0.0 \mathrm{~s}$. The numerical flume was also set using length $x$-direction $\left(L_{x}\right)=1.60 \mathrm{~cm}$, length $y$-direction $\left(L_{y}\right)=0.67 \mathrm{~cm}$, time interval $(\Delta t)=0.00001 \mathrm{~s}$, grid spacing $x$-direction $\left(\Delta_{x}\right)=0.005 \mathrm{~cm}$, grid spacing $y$-direction $\left(\Delta_{x}\right)=0.005 \mathrm{~cm}$, and frictionless bed while the manning coefficient $(n)=0$. The boundary conditions, in this case, are the same as case 1 . In addition, the building or column was assumed as wall and this made the velocity in $x$ and $y$ directions to be equal to 0 .

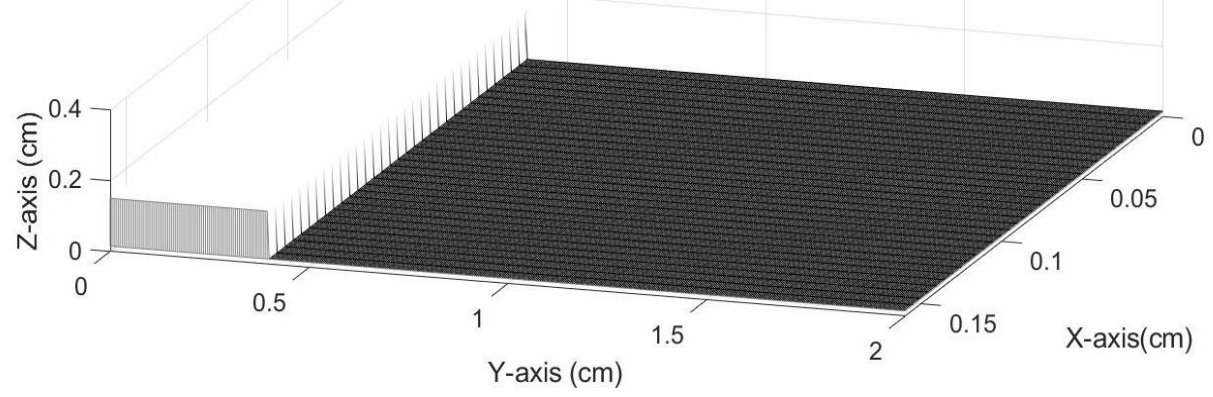

Figure 1. Set up for a simple dam-break problem 


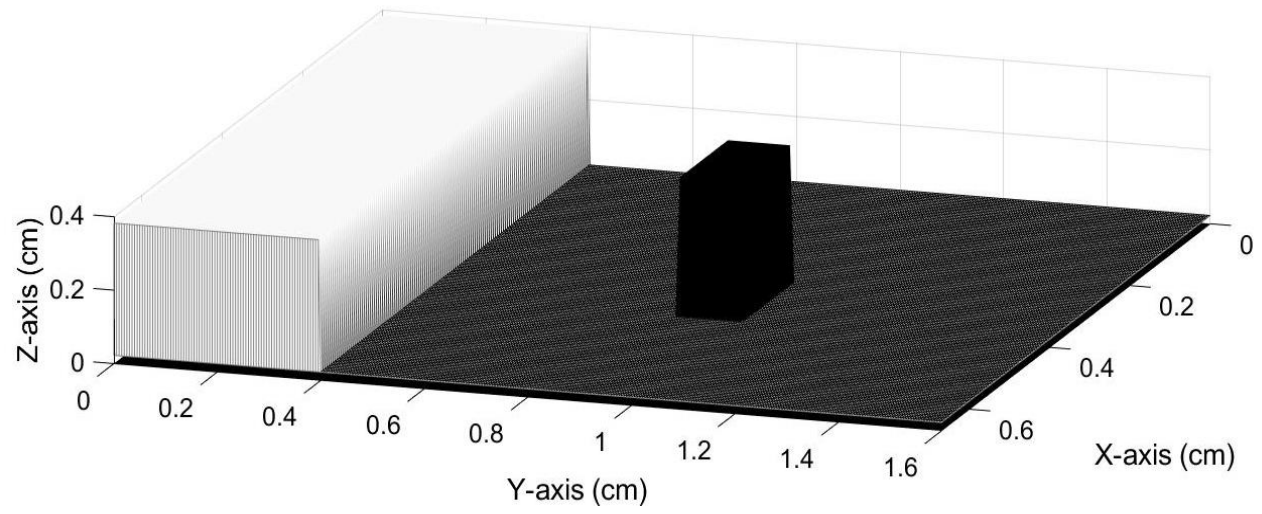

Figure 2. Set up for a dam break and column interactions problem

\section{RESULTS AND DISCUSSION}

\subsection{Simulation Results: Test Case 1}

The effect of friction was considered negligible in this study and this eliminated the diffusion rate. This was associated with the fact that the test was being developed on a laboratory scale with a smooth flume. Moreover, the use of Stoker analysis for model calibration led to the absence of friction and turbulence, thereby, making the source and diffusion rate to be zero. The evolution of water depth was examined in space and time after the collapse of the initial column of water at $t=0.0$ second as shown in Figure 1 and mentioned in Section 3. Figure 3 (a) and (b) show the water surface elevation and elevation contour at $t=0.05$ seconds after the simulation has started while Figure 4 (a) and (b) show the trend at $\mathrm{t}=0.10$ seconds and Figure 5 (a) and (b) at $t=1.00$ seconds.

Figure 3 and 4 show the water surface elevation at distance $x=0 \mathrm{~m}$ did not change or decrease and dam break wave was observed to have propagated to a distance of $x=0.45 \mathrm{~m}$ at $t=0.01$ seconds and $x=0.55 \mathrm{~m}$ at $t=0.1$ seconds. Figure 5 , however, shows a decrease in the water surface elevation in the upstream to $0.04 \mathrm{~m}$ at $t=1.0$ second after the simulation was initiated while the waves propagated to $x=1.42 \mathrm{~m}$.

Case 1 was modeled using numerical methods and was verified through a comparison with analytical solutions using the Stoker analytical method (Zendrato, et al., 2019).

Initial conditions (Equation (12) and (13)):

$\mathrm{h}(\mathrm{x})=\left\{\begin{array}{l}h_{l} \text { for } 0 m \leqslant x \leqslant x_{0} \\ h_{r} \text { for } x_{0} \leqslant x \leqslant L\end{array}\right.$

with,

$h_{l} \geqslant h_{r}$ and $u(x)=0 \mathrm{~m} / \mathrm{s}$

Water level, $h$, is provided in Equation (14) to (18).

$\mathrm{h}(\mathrm{t}, \mathrm{x})=\left\{\begin{array}{c}\frac{4}{9 g}\left(\sqrt{g h_{l}}-\frac{x-x_{0}}{2 t}\right)^{2} \\ c m^{2} / g \\ h_{r}\end{array} ; u(t, x)=\right.$

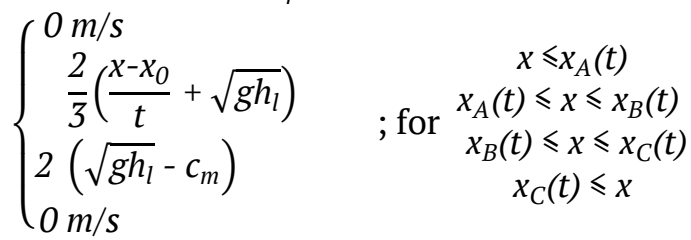

$\mathrm{h}(\mathrm{t}, \mathrm{x})=\left\{\begin{array}{c}\frac{4}{h_{l}}\left(\sqrt{g h_{l}}-\frac{x-x_{0}}{2 t}\right)^{2} \\ \mathrm{~cm}^{2} / g \\ h_{r}\end{array} ; u(t, x)=\right.$

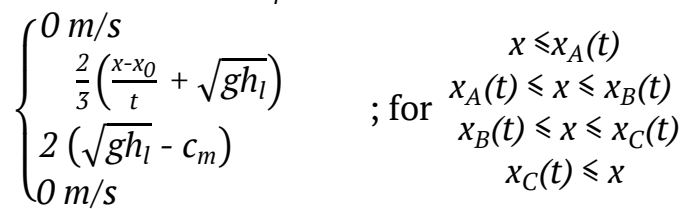


where:

$x_{A}(t)=x_{0}-t \sqrt{g h_{l}}$

$x_{B}(t)=x_{0}+t\left(2 \sqrt{g h_{l}}-3 c_{m}\right)$

$x_{C}(t)=x_{0}+t \frac{2 c_{m}^{2}\left(\sqrt{g h_{l}}-c_{m}\right)}{c_{m}^{2}-g h_{r}}$

$c_{m}=\sqrt{g h_{m}}$ where $h_{m}$ is expected to be between hd and hu. The assumptions made include 1) the base of the channel is flat, 2) dam break occurs suddenly, and 3 ) there is no friction. Therefore, it is possible to calculate the initial value using $h_{m}, c_{m}$ and later substituted to the Equation (19).

$-8 g h_{r} c_{m}^{2}\left(\sqrt{g h_{l}}-c_{m}\right)^{2}+\left(c_{m}^{2}-g h_{r}\right)^{2}\left(c_{m}^{2}+g h_{r}\right)=0$

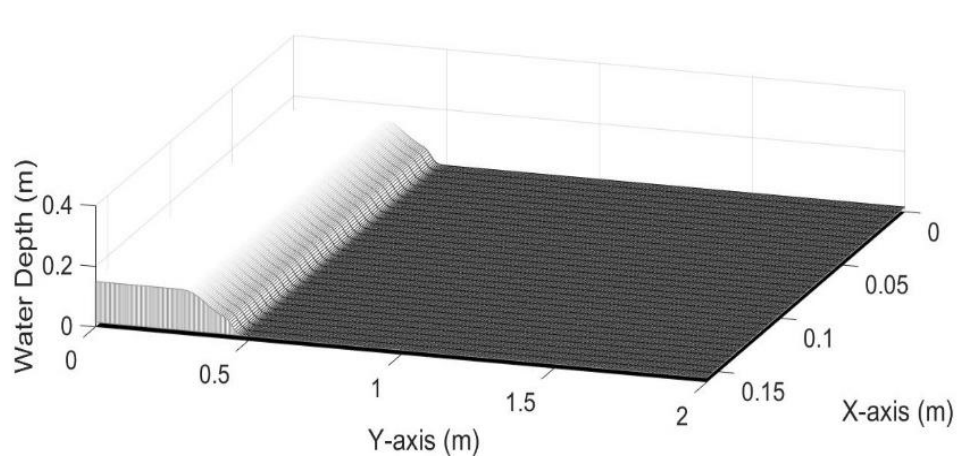

(a)

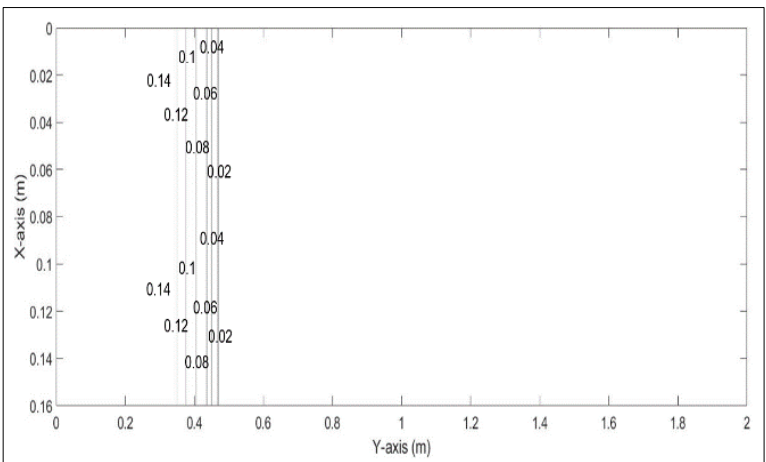

(b)

Figure 3. Water surface elevation (a) and elevation contour (b) at $t=0.05$ seconds after dam break

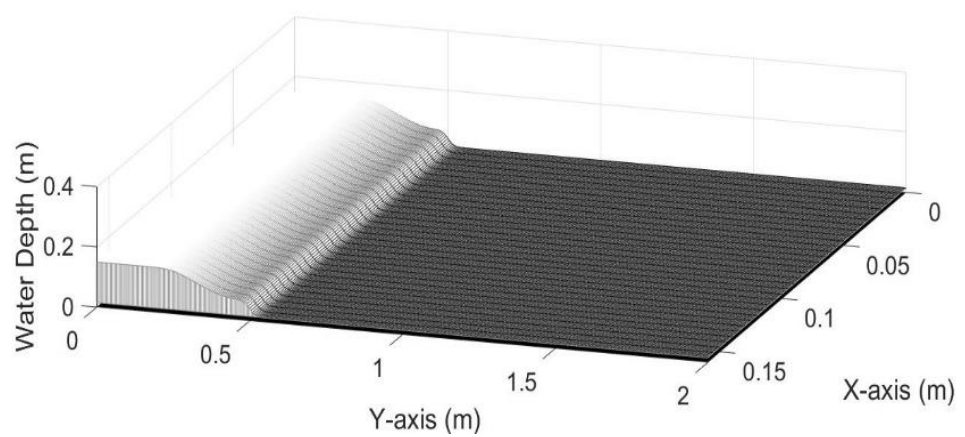

(a)

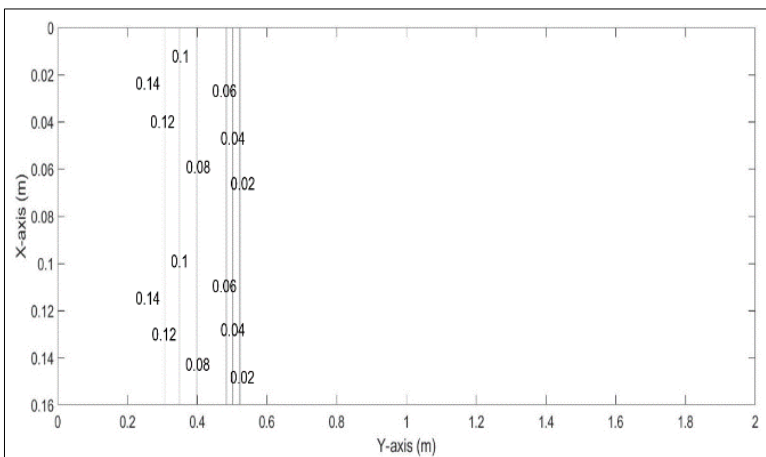

(b)

Figure 4. Water surface elevation (a) and elevation contour (b) at $t=0.10$ seconds after dam break

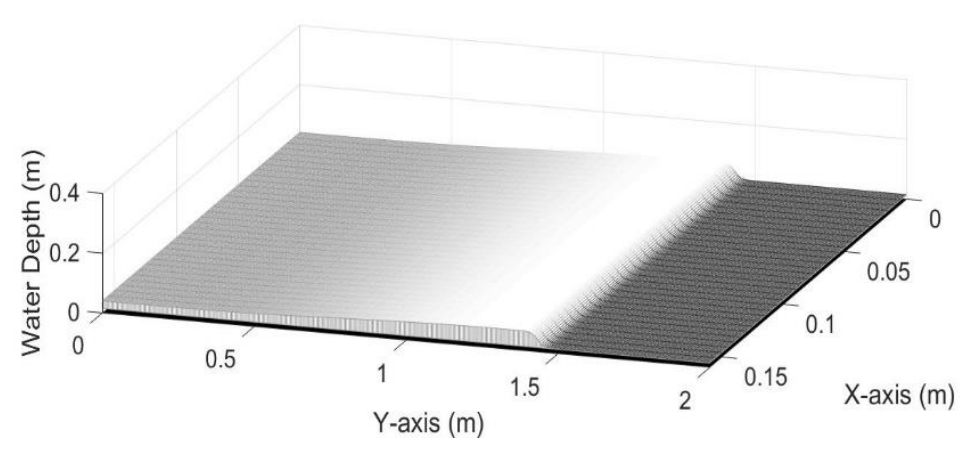

(a)

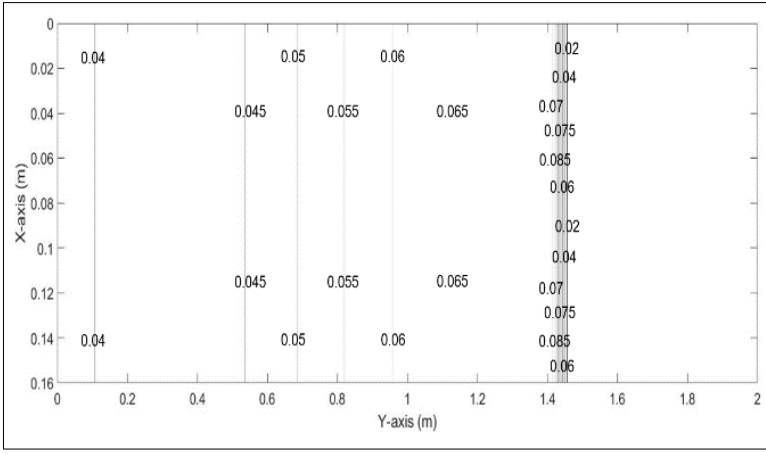

(b)

Figure 5. Water surface elevation (a) and elevation contour (b) at $t=1.00$ seconds after dam break 
The numerical and analytical methods were compared in this case through one-dimensional dam break case as shown in Figure 6 using length $(L)=2 \mathrm{~m}$, time interval $\left(\Delta_{t}\right)=0.0001 \mathrm{~s}$, and distance difference $\left(\Delta_{x}\right)=0.005 \mathrm{~m}$ as input parameters.

The RMSE value was calculated as presented in Table 1 to determine the differences in simulation results using numerical methods. The RMSE (Root Mean Square Error) is a measure of error based on the difference between two corresponding values with those close to 0 indicating closeness between the variations in model values and observational values. The RMSE is usually calculated using Equation (20).

$\operatorname{RSME}=\left(\frac{\sum\left(y_{i}-\bar{y}_{i}\right.}{n}\right)^{1 / 2}$

where, $y$ is the numerical model result value, $\bar{y}$ is the analytical model result value, $i$ is the sequence of data in database, and $n$ is the amount of data.
Table 1. RMSE Values

\begin{tabular}{lll}
\hline No. & Variable & RMSE \\
\hline 1 & Water level change $(\mathrm{t}=0.05 \mathrm{~s})$ & 0.00239 \\
2 & Water level change $(\mathrm{t}=0.10 \mathrm{~s})$ & 0.00242 \\
3 & Water level change $(\mathrm{t}=1.00 \mathrm{~s})$ & 0.00225 \\
\hline
\end{tabular}

The table shows the numerical model produced relatively small error values compared to the analytic model and this means it can be developed and used in Case 2.

\subsection{Simulation Results: Test Case 2}

The case of the dam break and column interactions have been previously simulated by other researchers using finite volume (Wang, et al., 2000) and SPH (Gomez, et al., 2010) models. The evolution of water depth was examined in space and time after the collapse of the initial column of water at $t=0.15$ seconds, $t=0.30$ seconds, $t=40$ seconds, and $t=0.60$ seconds after the start of the simulation as shown in Figure 7, 8, 9 and 10 and previously indicated in Section 3.

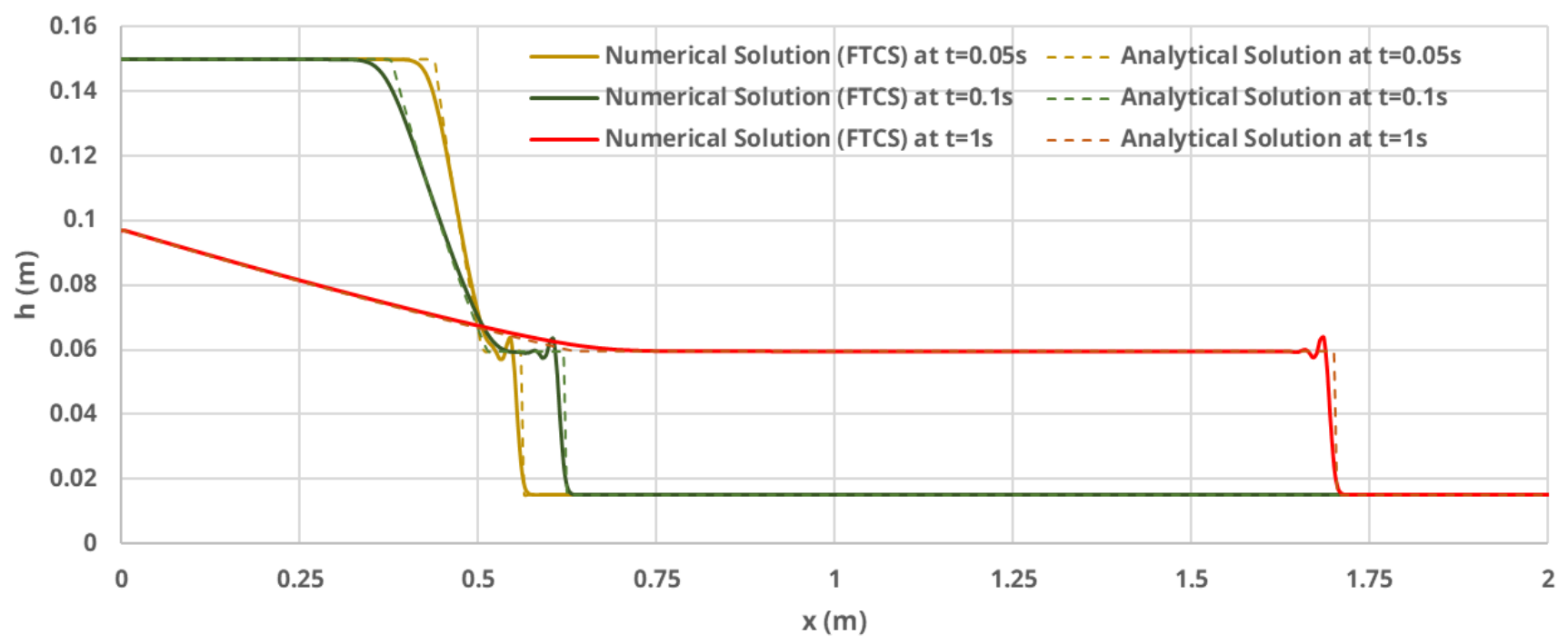

Figure 6. Comparison of water level profile changes etween numerical and analytical methods 
Figure 7 shows the position of the front-wave developed spatially at 0.15 seconds after the simulation was initiated with the dam break waves propagated to a distance of $x=0.65 \mathrm{~m}$ and surface water elevation at $x=0 \mathrm{~m}$ observed not to have changed or decreased. Meanwhile, Figure 8 shows the water propagation hitting the column at $t=0.30$ seconds with the surface water elevation in the upstream recorded to be $0.24 \mathrm{~m}$ while Figure 9 indicates the results at time $t=0.40$ seconds when the column has been hit by water. The simulation showed the water flow when hitting the column has a reflection effect and this led to an increase in the water surface in the upstream area due to the changes in velocity to form a wave. The same conditions were observed in a previous study by Sinha, et al. (2013) which also showed a reflection due to water flow hitting the column.
Figure 10 shows the results of the simulation at time $t=0.60$ seconds when the water has propagated after hitting the column. The flow was observed to have diffracted as it spreads and propagates around the column with the small friction on its surface not causing any difference in flow velocity as well as the water level between the flow and the surrounding. Moreover, the diffracted flow was discovered to have reunited at the downstream to form a whirlpool which later caused a lower water level behind the column as shown in the long section profile at the centerline of the flume in Figure 11. Several phenomena in this simulation proved the ability of the 2D model to show the changes in the water flow characteristics hitting a column due to the impact of a dam-break.

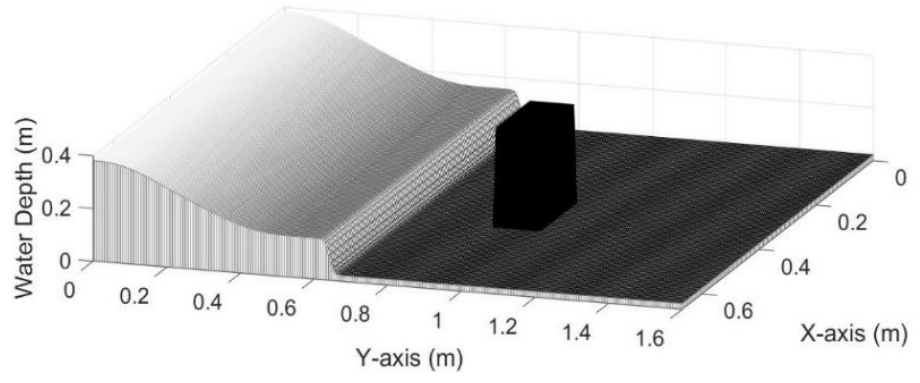

(a)

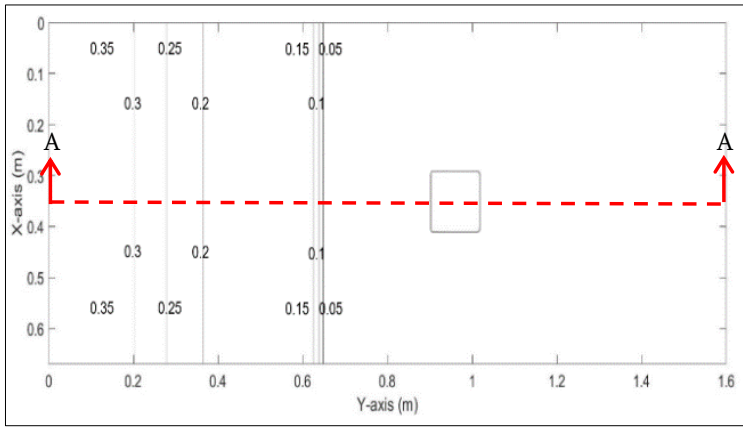

(b)

Figure 7. Water surface elevation (a) and elevation contour (b) at $t=0.15$ seconds after the collapse of the dam with prismatic column

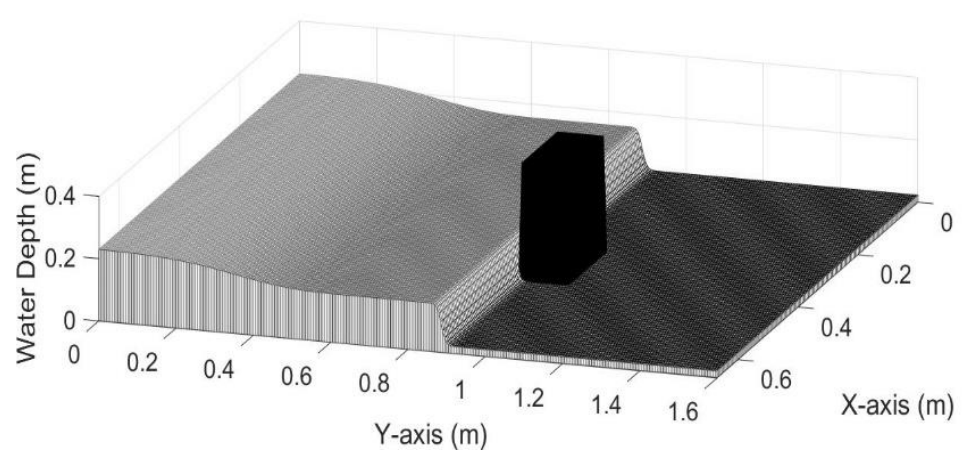

(a)

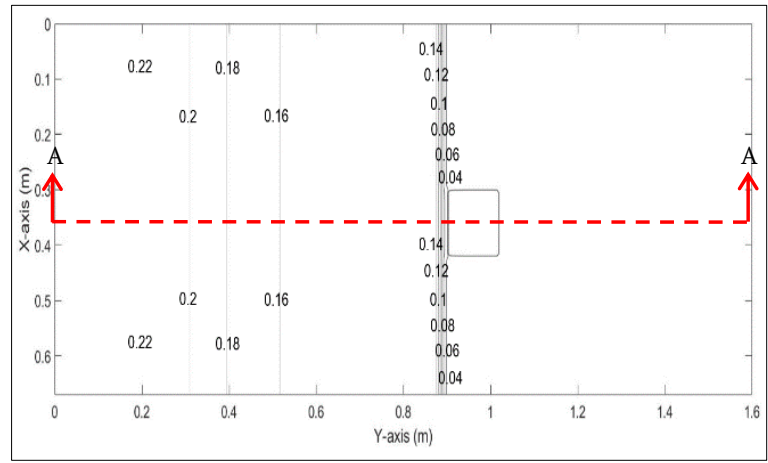

(b)

Figure 8. Water surface elevation (a) and elevation contour (b) at $t=0.30$ seconds after the collapse of the dam with prismatic column 


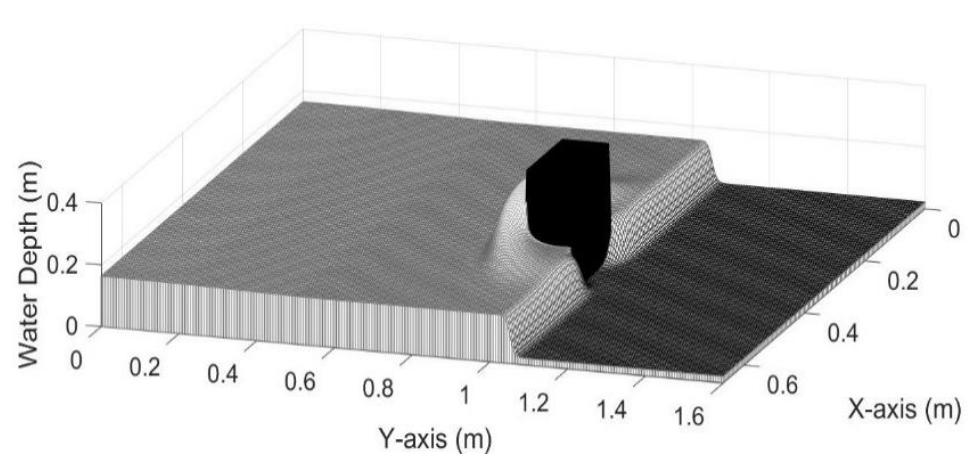

(a)

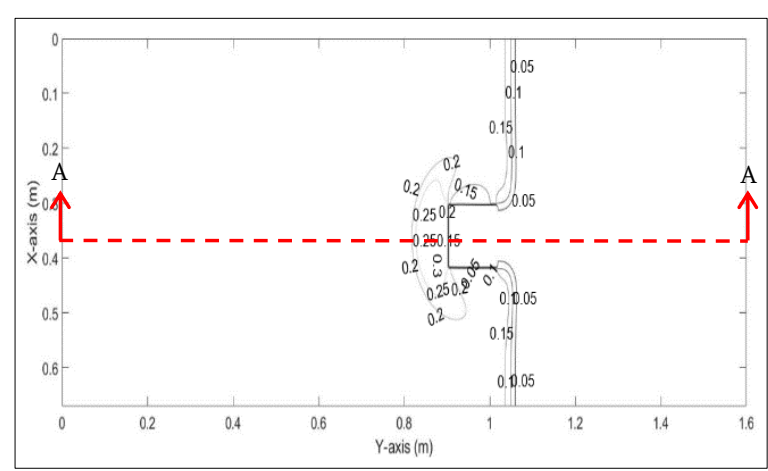

(b)

Figure 9. Water surface elevation (a) and elevation contour (b) at $t=0.40$ seconds after the collapse of the dam with prismatic column

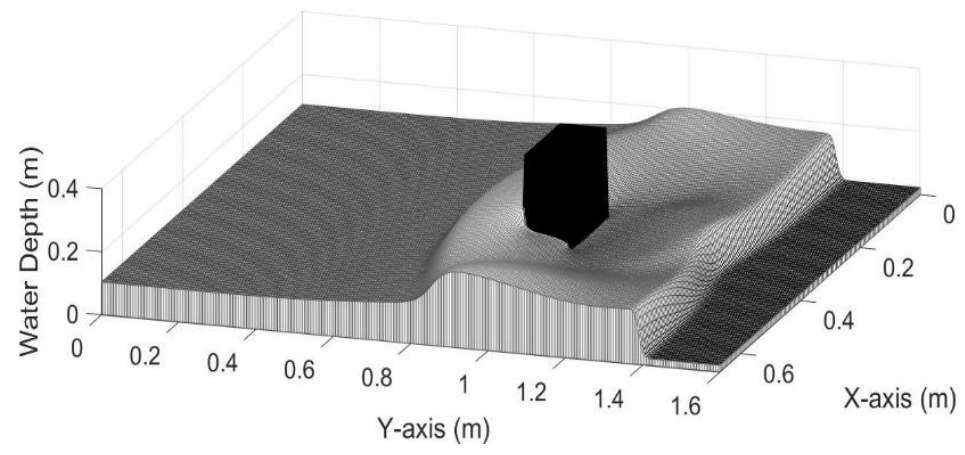

(a)

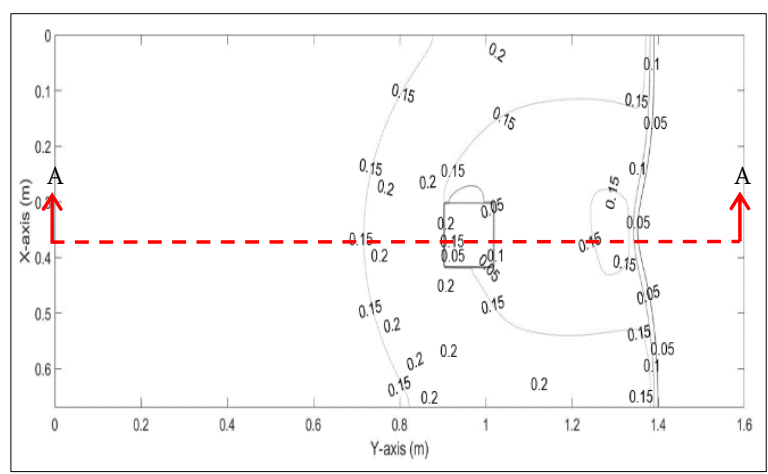

(b)

Figure 10. Water surface elevation (a) and elevation contour (b) at $t=0.60$ seconds after the collapse of the dam with prismatic column

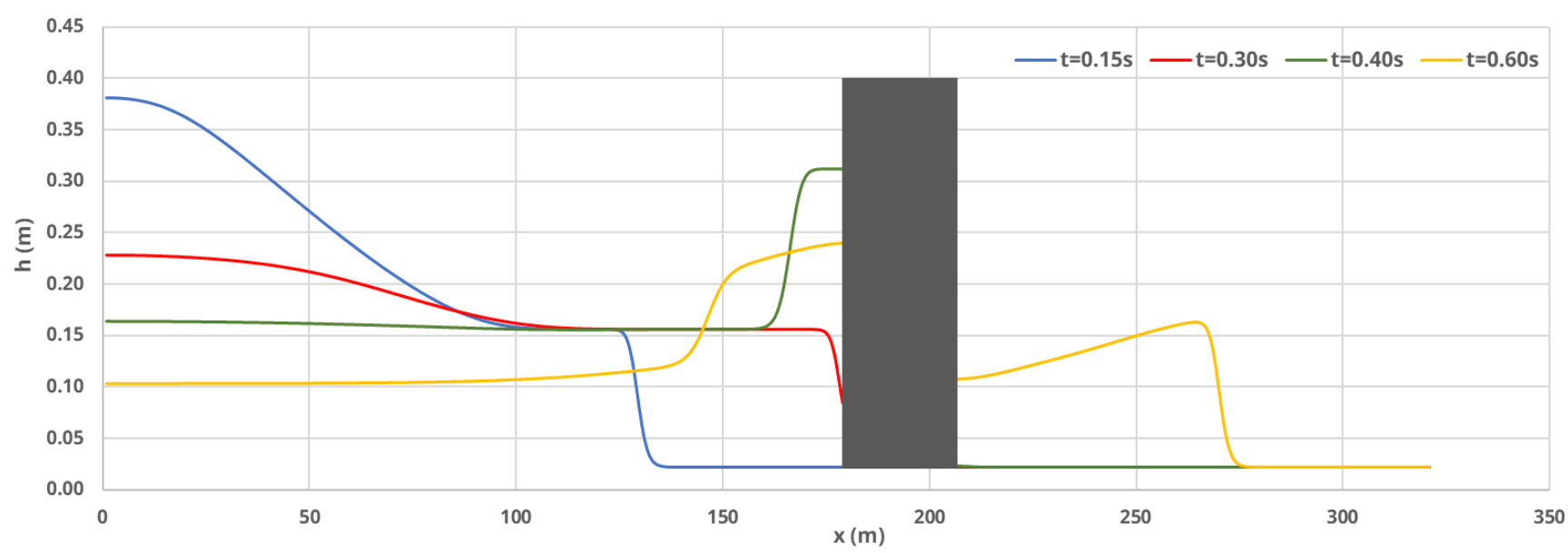

Figure 11. Water level profile at the centerline of the flume in case 2 (long section A-A)

\section{CONCLUSION}

The FTCS numerical scheme was successfully employed to solve the $2 \mathrm{D}$ shallow water equation with the use of a numerical filter to handle shock. The model was tested with an analytical dam break and good results were obtained after the comparison. It was further applied to simulate a dam break-induced flow on a structure and was also discovered to performed effectively and able to produce defined effects including reflection and diffraction. Furthermore, it is possible to extend and apply the model with the inclusion of the bed friction effect and also to evaluate the force of a dam break flow on a structure.

\section{DISCLAIMER}

The authors declare no conflict of interest. 


\section{ACKNOWLEDGMENT}

This study was supported by P3MI LPPM ITB and ITB multi-disciplinary research.

\section{REFERENCES}

Adityawan, M. B., and Tanaka, H., 2012. Bed Stress Assessment Under Solitary Wave Run-up. Earth, Planets and Space Journal, 64(10), pp. 945954.

Chen, A. S., Hsu, M. H., Chen, T. S., and Chang, T. J., 2005. An Integrated Inundation Model for Highly Developed Urban Areas. Water Science and Technology, 51(2), 221-229.

Farid, M., Yakti, B. P., Rizaldi, A., and Adityawan, M. B., 2016. Finite Difference Numerical Scheme for Simulating Dam Break Flow. The 5th HATHI International Seminar on Water Resilience in a Changing World.

Gomez-Gesteira, M., Rogers, B. D., Dalrymple, R. A., and Crespo, A. J. C., 2010. State-of-the-art of Classical SPH for Free-surface Flows. Journal of Hydraulic Research Extra Issue, 48, pp 6-27.

Harlan, D., Adityawan, M. B., Natakusumah, D. K., and Zendrato, N. L. H., 2019. Application of Numerical Filter to a Taylor Galerkin Finite
Element Model for Movable Bed Dam Break Flows. International Journal of Geomate, 16(57).

Kusuma, M. S. B., Farid, M., and Adityawan, M. B., 2008. Numerical Model Study of Two Dimension Flow Generated by a Dam Break. International Conference on Earthquake Engineering and Disaster Mitigation.

Maitsa, T., R, Mardika, M. G., I., Adityawan, M. B., and Harlan D., 2019. 2D Numerical Simulation of Urban Dam Break and Its Effect to Building using Lax Scheme with Numerical Filter. International Conference on Earthquake Engineering and Disaster Mitigation.

Sinha, S., Rode, M., and Borchardt, D., 2013. Numerical Modeling of Shallow Water Equations: A Comparative Study Between Mesh-Less and MeshFull Methods. Proceedings of 2013 IAHR World Congress.

Wang, J.S., Ni, H. G., and He, Y. S., 2000. Finitedifference TVD Scheme for Computation of Dambreak Problems. Journal of Hydraulic Engineering, pp. 253-262.

Zendrato, N. L. H., Harlan, D., Adityawan, M. B., and Natakusumah, D. K., 2019. 1D Numerical Modelling of Dam Break Using Finite Element Method. MATEC Web of Conferences, 270, 04022 
[This page is intentionally left blank] 